\title{
EFEKTIVITAS PENGGUNAAN SISTEM INFORMASI AKUNTANSI TERHADAP PENINGKATAN KINERJA PEGAWAI PADA KANTOR SAMSAT KABUPATEN GOWA
}

\author{
Rahmadhani \\ Akuntansi, Universitas Muhammadiyah Makassar \\ Email: daniefherry@gmail.com \\ Idra wahyuni \\ Akuntansi, Universitas Muhammadiyah Makassar \\ Email: idrawahyuni@unismuh.ac.id
}

(Diterima: 30-Januari-2018; direvisi: 15-Februari-2018; dipublikasikan: 18-April-2018)

\begin{abstract}
:
This study aims to analyze the effect of the effectiveness of the use of accounting information systems to improve employee performance. Location of the research conducted at Samsat the South Sulawesi in Gowa region. Data collection using survey with questionnaries to users of employee Samsat the South Sulawesi in Gowa region.. Sampling is done by simple random sampling. The questonnaries was completed by 30 respondents and data analyzed with analyzed by using descriptive statistic analysis and simple linear regression analysis through Statistical Product and Service Solution (SPSS) version 20. The research result indicates that analysis the effectiveness of the use of accounting information system had positive and significant influence to the improvement of employee performance at Samsat the South Sulawesi in Gowa region.
\end{abstract}

Kwords: Accounting Information System; Performance

\begin{abstract}
Abstrak:
Penelitian ini bertujuan untuk menganalisis pengaruh efektifitas penggunaan sistem informasi akuntansi terhadap peningkatan kinerja pegawai. Penelitian ini dilakukan pada kantor Samsat Kabupaten Gowa Provinsi Sulawesi Selatan. Data yang digunakan dalam penelitian ini adalah data primer. Pengumpulan data dilakukan melalui survei dengan menyebarkan kuesioner pada pegawai yang bekerja pada kantor Samsat Kabupaten Gowa Provinsi Sulawesi Selatan yang berjumlah 30 responden. Pengambilan sampel dilalukan dengan metode simple random sampling. Kuesioner diisi oleh 30 responden dan data di analisis dengan menggunakan analisis statistik deksriptif dan analisis regresi linier sederhana melalui bantuan Statistical Product and Service Solution (SPSS) versi 20. Hasil menunjukkan bahwa berdasarkan hasil analisis regresi linier sederhana efektifitas penggunan sistem informasi akuntansi berpengaruh positif dan signifikan terhadap peningkatan kinerja pegawai pada kantor Samsat Kabupaten Gowa Provinsi Sulawesi Selatan.
\end{abstract}

Kata kunci: Sistem Informasi Akuntansi; Kinerja

\section{PENDAHULUAN}

Perkembangan teknologi dari pengaruh globalisasi sekarang ini begitu pesat yang diikuti dengan perkembangan sistem informasi yang berbasis teknologi, telah menyebabkan terjadinya perubahan-perubahan yang begitu cepat di dalam berbagai bidang. Perkembangan teknologi informasi mempunyai dampak yang sangat signifikan terhadap sistem informasi akuntansi dalam suatu organisasi bisnis, khususnya dalam 
pemrosesan data yang mengalami perubahan dari sistem manual digantikan dengan sistem komputer sebagai alat pemrosesan data.

Penggunaan teknologi informasi diera sekarang ini merupakan elemen penting dalam aktivitas perusahaan atau lembaga. Sistem informasi membawa pengaruh besar terhadap hampir semua aspek dalam pengelolaan bisnis, termasuk dalam pengelolaan keuangan. Perkembangan sebuah sistem informasi juga perlu didukung oleh banyak faktor yang diharapkan bisa memberikan keberhasilan dari sistem tersebut. Keberhasilan aplikasi sistem informasi pada suatu perusahaan dipengaruhi dari cara sistem itu dijalankan, tingkat kemudahan sistem itu bagi para pemakainya, dan pemanfaatan teknologi yang digunakan.

Goodhue dalam Panggeso (2014) mencoba mengukur keberhasilan sistem informasi yang diimplementasikan dalam organisasi dengan menggunakan evaluasi pemakai. Pengukuran ini menyatakan bahwa jika evaluasi pemakai atas teknologi cocok dengan kemampuan dan tuntutan dalam tugas pemakai maka akan memberikan dorongan pemakai memanfaatkan teknologi.

Evaluasi pemakai atas kecocokan tugas teknologi menjadi penting artinya berkaitan dengan pencapaian kinerja individual yang tinggi. Oleh sebab itu, penerapan teknologi dalam sistem informasi akuntansi hendaknya mempertimbangkan kemampuan pemakai sistem sehingga teknologi itu sendiri dan diterapkan sesuai dengan tugas, kemampuan pemakai seta dapat dimanfaatkan secara optimal. Dengan demikian aplikasi teknologi sistem informasi tersebut dapat meningkatkan kinerja individual yang akan berdampak kekinerja lembaga itu sendiri.

Meningkatnya perkembangan dunia dan kemajuan teknologi, membuat para pemakai informasi menginginkan kecepatan arus informasi dengan segera diterima untuk diantisipasi dalam rangka pengambilan keputusan. Teknologi informasi yang dapat diakses dengan mudah memberikan arus informasi dan kebutuhan akan informasi yang cepat, andal, dan akurat dalam kondisi lingkungan yang penuh dengan ketidakpastian mutlak diperlukan. Kebutuhan tersebut dapat dipenuhi jika suatu lembaga atau perusahaan berani melakukan investasi dibidang teknologi informasi, dengan tujuan untuk dapat memberikan kontribusi yang positif terhadap kinerja individual anggota organisasi dan institusinya.

Penelitian Mahmood dan Mann yang dikutip Panggeso (2014) memberikan bukti secara empiris bahwa investasi di bidang teknologi informasi memberikan kontribusi terhadap kinerja dan produktivitas suatu organisasi. Teknologi informasi khususnya teknologi komputer sangat berpotensi untuk memperbaiki performa individu dan organisasi, oleh sebab itu banyak pengambil keputusan menginvestasikan dananya untuk teknologi informasi. Dengan demikian pemakai atau penguna merupakan bagian yang tidak dapat dilepaskan dari keberhasilan penerapan suatu teknologi.

Irwansyah yang dikutip Sari (2008) mengemukakan bahwa penggunaan teknologi 
dalam sistem informasi perusahaan hendaknya mempertimbangkan pemakai. Tidak jarang ditemukan bahwa teknologi yang diterapkan dalam sistem informasi sering tidak tepat atau tidak dimanfaatkan secara maksimal oleh individu pemakai sistem informasi, sehingga sistem informasi kurang memberikan manfaat dalam meningkatkan kinerja individual.

Menurut Nelson yang dikutip Sari (2008) diterimanya suatu teknologi komputer tergantung pada teknologi itu sendiri, tingkat skill, dan expertise dari individu yang menggunakannya. Bagi perusahaan aplikasi teknologi yang tepat akan mendatangkan competitive advantage, sedangkan keahlian yang dimiliki akan meningkatkan kinerja individu yang bersangkutan.

Selain keahlian yang dimiliki oleh individu, kepercayaan juga diperlukan oleh pemakai teknologi sistem informasi agar pemakai tersebut merasa bahwa teknologi sistem informasi yang diterapkan dapat meningkatkan kinerjanya dalam menjalankan kegiatan operasional suatu lembaga atau perusahaan. Berdasarkan pemaparan di atas, maka dilakukan penelitian dengan tujuan untuk mengetahui serta menganalisis besarnya pengaruh efektivitas teknologi sistem informasi akuntansi terhadap kinerja pegawai instansi pemerintahan pada kantor Samsat Wilayah Kabupaten Gowa Provinsi Sulawesi Selatan.

Berdasarkan uraian research gap diatas, maka pengembangan hipotesis penelitian ini adalah efektifitas penggunaan sistem informasi akuntansi berpengaruh terhadap peningkatan kinerja pegawai pada kantor Samsat Kabupaten Gowa Provinsi Sulawesi Selatan.

\section{METODE}

\section{Pendekatan Penelitian}

Pendekatan penelitian ini adalah dengan metode kuantitatif. Penelitian kuantitatif bertujuan untuk menunjukkan hubungan antar variabel, menguji teori dan mencari generalisasi yang mempunyai nilai prediktif.

\section{Lokasi dan Waktu Penelitian}

Penelitian ini dilakukan pada kantor Samsat Wilayah Kabupaten Gowa, yang beralamat di jalan Tamanurung Raya Kecamatan Somba Opu Kabupaten Gowa Provinsi Sulawesi Selatan. Sedangkan waktu yang digunakan selama 3 bulan penelitian yaitu bulan September sampai dengan November 2017.

\section{Populasi dan Sampel}

Populasi dalam penelitian ini adalah seluruh karyawan/pegawai pada kantor Samsat Wilayah Kabupaten Gowa Provinsi Sulawesi Selatan. Pemilihan sampel dilakukan dengan metode random sampling. Sampel dalam penelitian ini adalah pegawai yang menggunakan sistem informasi akuntansi dalam pekerjaan sehari-hari. Jadi total sampel dalam penelitian ini sebanyak 30 responden.

\section{Metode Pengumpulan Data}

Data yang digunakan dalam penelitian ini menggunakan data primer dan data sekunder. Data primer yaitu data yang dikumpulkan melalui survei kuesioner yang diantar dan diambil sendiri oleh peneliti. Data sekunder yaitu data yang diperoleh berupa informasi tertulis, misalnya berupa artikel, jurnal, dan melalui internet.

\section{Metode Analisis Data}


Hipotesis dalam penelitian ini diuji dengan menggunakan uji kualitas data, uji asumsi klasik, uji hiptesis dan analisis deskriptif. Alat analisis yang digunakan yaitu software SPSS Ver 20. Model regresi dalam penelitian ini ditunjukan dalam persamaan berikut ini.

$$
\mathrm{Y}=\alpha+\beta_{1} \mathrm{X}_{1}+\varepsilon
$$

Keterangan:

$$
\begin{aligned}
\mathrm{Y} & =\text { Kinerja Pegawai } \\
\mathrm{X}_{1} & =\text { Penggunaan Sistem } \\
\alpha & =\text { Informasi Akuntansi } \\
\alpha & \text { Konstanta } \\
\beta_{1}= & \text { Koefisien Penggunaan } \\
\varepsilon & \text { Sistem Informasi Akuntansi } \\
\varepsilon & \text { Error (tingkat kesalahan) }
\end{aligned}
$$

\section{HASIL DAN PEMBAHASAN Uji Statistik Deskriptif}

Statistik deskriptif menggambarkan karakteristik umum dari sampel yang digunakan dalam penelitian ini dengan lebih rinci sehingga dapat diketahui nilai minimum, nilai maksimum, nilai rata-rata dan standar deviasi dari masing-masing variabel yaitu efektivitas penggunaan sistem informasi akuntansi dan kinerja pegawai. Hasil uji statistik deskriptif untuk setiap variabel disajikan pada tabel 1 sebagai berikut.

\section{Tabel 1}

\section{Descriptive Statistics}

$$
\text { N } \underset{\text { um }}{\operatorname{Minim}} \underset{\text { um }}{\operatorname{Maxim}} \text { Mean } \begin{gathered}
\text { Std. } \\
\text { Deviation }
\end{gathered}
$$

\begin{tabular}{cccccc}
\cline { 2 - 5 } $\begin{array}{c}\text { Efektivitas_- } \\
\text { Penggunaan }\end{array}$ & 30 & 31 & 45 & 40.43 & 3.431 \\
$\begin{array}{c}\text { _SIA } \\
\text { Kinerja_Peg }\end{array}$ & 30 & 35 & 45 & 40.53 & 3.115 \\
awai & & & & & \\
$\begin{array}{c}\text { Valid N } \\
\text { (listwise) }\end{array}$ & 30 & & & & \\
\hline
\end{tabular}

\section{Sumber : Data Diolah SPSS (2017)}

Dari hasil tabel 1 menggambarkan nilai setiap variabel dari 30 responden. Diketahui variabel efektifitas penggunaan

\begin{tabular}{|c|c|c|c|c|}
\hline Variabel & Pernyataan & r hitung & $r$ tabel & Keterangan \\
\hline \multirow{10}{*}{$\begin{array}{l}\text { Penggunaan } \\
\text { Sistem } \\
\text { Informasi } \\
\text { Akuntansi } \\
\quad(\mathrm{X})\end{array}$} & SIA_1 & 0,656 & \multirow{10}{*}{0,361} & Valid \\
\hline & SIA_2 & 0,527 & & Valid \\
\hline & SIA_3 & 0,504 & & Valid \\
\hline & SIA_4 & 0,718 & & Valid \\
\hline & SIA_5 & 0,625 & & Valid \\
\hline & SIA_6 & 0,463 & & Valid \\
\hline & SIA_7 & 0,540 & & Valid \\
\hline & SIA_8 & 0,527 & & Valid \\
\hline & SIA_9 & 0,536 & & Valid \\
\hline & SIA_10 & 0,539 & & Valid \\
\hline Kinerja Pegawai & KP_1 & 0,656 & 0,361 & Valid \\
\hline
\end{tabular}
sistem informasi akuntansi diperoleh nilai minimum 31, nilai maksimal 45 dan nilai rata-rata 40,43 . Sedangkan variabel kinerja pegawai diperoleh nilai minimum 35 , nilai maksimal 45 dan nilai rata-rata 40,53.

\section{Uji Validitas}

\section{Tabel 2}

\section{Uji Validitas Data}




\begin{tabular}{|c|c|c|c|}
\hline \multirow[t]{9}{*}{$(\mathrm{Y})$} & KP_2 & 0,527 & Valid \\
\hline & $\mathrm{KP} \_3$ & 0,504 & Valid \\
\hline & KP_4 & 0,718 & Valid \\
\hline & KP_5 & 0,625 & Valid \\
\hline & KP_6 & 0,463 & Valid \\
\hline & KP_7 & 0,540 & Valid \\
\hline & KP_8 & 0,527 & Valid \\
\hline & KP_9 & 0,536 & Valid \\
\hline & $\mathrm{KP} \_10$ & 0,539 & Valid \\
\hline
\end{tabular}

Sumber: Data Diolah (2017)

Berdasarkan hasil output di atas diketahui $\mathrm{r}$ hitung variabel $\mathrm{X}$ untuk item 1 adalah sebesar 0,656 , item 2 sebesar 0,527 , item 3 sebesar 0,504 , item 4 sebesar 0,718 , item 5 sebesar 0,625 , item 6 sebesar 0,463 , item 7 sebesar 0,540 , item 8 sebesar 0,527 , item 9 sebesar 0,536 dan item 10 sebesar 0,539. Hasil tersebut menunjukan bahwa pertanyaan nomor 1 sampai nomor 10 valid karena angkanya lebih besar dari $r$ tabel $(0,361)$.

Berdasarkan hasil output di atas diketahui $\mathrm{r}$ hitung variabel $\mathrm{Y}$ untuk item 1 adalah sebesar 0,414 , item 2 sebesar 0,718 , item 3 sebesar 0,598 , item 4 sebesar 0,400 , item 5 sebesar

Dari hasil regresi yang diperoleh, maka dapat dijelaskan regresi sederhana sebagai berikut:

$$
Y=22,996+0,434 X
$$

Berdasarkan perhitungan di atas maka dapat dijelaskan sebagai berikut;

a) Koefisien konstanta $(\alpha)=22,996$ yang berarti bahwa jika tidak ada pengaruh $\mathrm{X}$, maka kinerja individual sebesar 22,996\% .

b) Koefisien regresi $\mathrm{X}$ sebesar 0,434 menyatakan bahwa setiap peningkatan tanggapan responden mengenai efektivitas penggunaan sistem informasi akuntansi
0,538, item 6 sebesar 0,515 , item 7 sebesar 0,480, item 8 sebesar 0,377, item 9 sebesar 0,639 dan item 10 sebesar 0,562. Hasil tersebut menunjukan bahwa pertanyaan nomor 1 sampai nomor 10 valid karena angkanya lebih besar dari $r$ tabel $(0,361)$.

\section{Uji Regresi Linier Sederhana}

\begin{tabular}{llcr}
\hline & \multicolumn{1}{c}{ Model } & \multicolumn{2}{c}{ Unstandardized } \\
& & \multicolumn{2}{c}{ Coefficients } \\
& B & Std. Error \\
\hline 1 & $\begin{array}{l}\text { (Constant) } \\
\text { efektivitas_penggunaan } \\
\text { _sia }\end{array}$ & 22.996 & 6.117 \\
\hline
\end{tabular}

Sumber : data diolah

sebesar satu satuan akan meningkatkan kinerja individual sebesar $0,434 \%$. 


\section{Uji $t$}

\section{Tabel 4}

\begin{tabular}{|c|c|c|c|c|c|c|}
\hline \multicolumn{7}{|c|}{ Coefficients $^{\mathrm{a}}$} \\
\hline & \multirow{2}{*}{ Model } & \multicolumn{2}{|c|}{$\begin{array}{l}\text { Unstandardized } \\
\text { Coefficients }\end{array}$} & \multirow{2}{*}{$\begin{array}{c}\text { Standardized } \\
\text { Coefficients } \\
\text { Beta }\end{array}$} & \multirow{2}{*}{$\mathrm{t}$} & \multirow{2}{*}{ Sig. } \\
\hline & & $\mathrm{B}$ & Std. Error & & & \\
\hline & (Constant) & 22.996 & 6.117 & & 3.759 & .001 \\
\hline \multicolumn{7}{|c|}{1} \\
\hline & efektivitas_penggunaan_sia & .434 & .151 & .478 & 2.877 & .008 \\
\hline
\end{tabular}

a. Dependent Variable: kinerja_pegawai Sumber: Data Diolah (2017)

Secara parsial variabel efektivitas penggunaan sistem informasi akuntansi (X) menunjukkan nilai $\mathrm{t}_{\text {hitung }}(2,877)>\mathrm{t}_{\text {tabel }}(1,701)$ selain itu memiliki nilai $\rho=0,008<0,05$. Hal ini berarti secara parsial variabel efektivitas penggunaan sistem informasi akuntansi mempunyai pengaruh yang positif dan signifikan terhadap kinerja pegawai kantor Samsat Wilayah Kabupaten Gowa Provinsi Sulawesi Selatan.

Berdasarkan hasil analisis data di atas, terlihat bahwa variabel independen, yakni efektivitas penggunaan sistem informasi akuntansi terhadap variabel dependen kinerja pegawai berpengaruh baik. Maka dapat disimpulkan bahwa hipotesis efektivitas penggunaan sistem informasi akuntansi berpengaruh terhadap kinerja pegawai. Hasil penelitian ini sesuai dengan penelitian yang dilakukan oleh Sari (2008) yang meneliti tentang efektifitas penggunaan teknologi sistem informasi dan kepercayaan pada teknologi sistem informasi terhadap kinerja individual. Dari penelitian ini ditemukan bahwa efektifitas penggunaan teknologi sistem informasi dan kepercayaan pada teknologi sistem informasi memiliki pengaruh yang positif terhadap kinerja individual. Demikian pula dengan penelitian yang dilakukan oleh Panggeso (2014) yang meneliti tentang efektifitas penggunaan dan kepercayaan atas teknologi sistem informasi terhadap kinerja individual. Dari penelitian ini ditemukan bahwa efektifitas penggunaan teknologi sistem informasi akuntansi terhadap kinerja karyawan memiliki pengaruh yang positif terhadap kinerja individual.

Dengan demikian, sistem informasi akuntansi berpengaruh positif terhadap kinerja individual pada pegawai atau staf. Hal ini disebabkan sistem informasi akuntansi berupa program informasi dalam instansi sangat mempengaruhi dalam implementasi sistem informasi pada instansi atau perusahaan. Sistem informasi akuntasi memberikan bantuan yang cukup bernilai dalam hal pembuatan keputusan, selain itu dapat membantu para penggunanya untuk dapat bekerja lebih produktif dan efisien. Dengan lebih banyak fasilitas pendukung berupa sistem informasi akuntansi yang disediakan bagi pemakai maka semakin memudahkan pemakai mengakses data yang dibutuhkan untuk 
penyelesaian tugas individu dalam instansi atau perusahaan.

Dengan pemanfaatan sistem informasi akuntansi yang tepat dan didukung oleh kemampuan personil yang mengoperasikannya dapat meningkatkan kinerja instansi maupun kinerja pegawai yang bersangkutan. Penggunaan sistem informasi akuntansi dapat dikatakan memiliki manfaat yang besar jika pemakai merasa bahwa dengan penggunaan sistem informasi akuntansi tersebut, tugas-tugas yang diemban dan dilakukan dapat diselesaikan dengan lebih mudah dan cepat. Karena tugastugas relatif mudah dan cepat dikerjakan maka diharapkan kinerja juga akan meningkat.

\section{SIMPULAN DAN SARAN}

Dari analisis hasil penelitian dan pembahsan, maka dapat ditarik kesimpulan yaitu efektivitas penggunaan sistem informasi akuntansi menunjukkan nilai $t_{\text {hitung }}$ 2,877 lebih besar dari tabel 1,701 maka Ho diterima, selain itu memiliki probabilitas $(\rho)$ value $=0,008$ lebih kecil dari 0,05 maka Ho diterima. Sehingga dapat disimpulkan bahwa efektivitas penggunaan sistem informasi akuntansi berpengaruh positif dan signifikan terhadap kinerja pegawai pada kantor Samsat Wilayah Kabupaten Gowa sehingga hipotesis dalam penelitian ini diterima. Jadi dengan adanya penerapan sistem informasi akuntansi pada instansi pemerintahan sangat berpengaruh terhadap kinerja pegawai pada kantor Samsat Wilayah Kabupaten Gowa Provinsi Sulawesi Selatan.

Berdasarkan kesimpulan di atas, disarankan pada penelitian selanjutnya untuk lebih meneliti secara mendalam pengaruh efektifitas penggunaan sistem informasi seperti menambahkan variabel umur, tingkat pendidikan, dan gender untuk mendapatkan hasil prediksi yang berbeda. Untuk mendapatkan hasil generalisasi yang lebih baik, maka disarankan bagi penelitian selanjutnya untuk mengambil jumlah responden yang lebih banyak.

\section{DAFTAR RUJUKAN}

Alannita, Ni Putu. 2014. Pengaruh Kecanggihan Teknologi Informasi, Partisipasi Manajemen, dan Kemampuan Teknik Pemakai Sistem Informasi Akuntansi pada Kinerja Individu. Jurnal Ilmiah Akuntansi dan Bisnis Universitas Udayana.

Antasari, Kadek C. 2015. Pengaruh Efektivitas Sistem Informasi Akuntansi dan penggunaan Teknologi Informasi pada Kinerja Individual dengan Kepuasan Kerja sebagai Variabel Pemoderasi. Jurnal Akuntansi niversitas Udayana.

Briliantien, Iramaya. 2008. Faktor-Faktor yang Mempengaruhi Kinerja Sistem Informasi Akuntansi pada Bank Umum Pemerintahan Di Wilayah Surabaya dan Sidoarjo. Jurnal Akuntani Universitas Gunadarma.

Krismiaji. 2010. Sistem Informasi Akuntansi, Edisi Ketiga. UPP Sekolah Tinggi Ilmu Manajemen YKPM: Yogykarta.

Krismianti, Wahyu. 2009. Analisis Pengaruh Efektifitas Sistem Informasi Akuntansi Terhadap Kinerja Individual Pegawai PT. Kim Eng Sekuritas Indonesia. Jurnal Akuntansi Universitas Gunadarma.

Panggeso, Novia F. 2014. Efektifitas Penggunaan dan Kepercayaan Atas Sistem Informasi Akuntansi Terhadap Kinerja Karyawan Bank SulSel Di Makassar. Jurnal Akuntansi Universitas Hasanuddin.

Prabowo, Rizki R, 2013 Faktor-Faktor yang Memengaruhi Kinerja Sistem Informasi Akuntansi Akuntansi Di Bank Umum Kota Surakarta. Jurnal FKIP Akuntansi Universitas Sebelas Maret.

Pratama, Gede Aditya P. 2013. Keahlian Pemakai Komputer dan Kenyamanan Fisik dan Tingkat Efektivitas Sistem 
Informasi Akuntansi Terhadap Kinerja Karyawan. Jurnal Akuntansi Universitas Udayana.

Sahusilawane, Wildoms. 2014. Pengaruh Partisipasi Pemakai dan Dukungan Atasan Terhadap Kinerja Sistem Informasi Akuntansi pada Bank Umum Pemerintahan. Jurnal Organisasi dan Manajemen Fakultas Ekonomi Universitas Terbuka.

Sari, Maria M.Ratna. 2008. Pengaruh Efektivitas Penggunaan dan Kepercayaan Terhadap Teknologi Sistem Informasi Akuntansi Terhadap Kinerja Individual Pada Pasar Swalayan Di Kota Denpasar. Jurnal Ilmiah Akuntansi dan Bisnis Universitas Udayana.

Sugiartini, Ni Made. 2015. Pengaruh Efektivitas Teknologi Sistem Informasi Akuntansi pada Kinerja Individual dengan Budaya Organisasi sebagai Pemoderasi. Jurnal Akuntansi niversitas Udayana.

Winarno, Wing W. 2006. Sistem Informasi Akuntansi. Edisi Kedua. UPP Sekolah Tinggi Ilmu Manajemen YKPM : Yogyakarta. 